\title{
Acute pseudeomembran candidiasis in a patient with high erythrocyte dedimentation rate and leucocyte
}

\author{
A Bakar ${ }^{1}$, V Ningrum $^{2}$, Khairiati $^{3}$, A Parlindungan $^{4}$, T Wulandari $^{5}$, Shih-Chieh Lee ${ }^{5}$ \\ \{abuba.mmed@gmail.com\} \\ ${ }^{1}$ Department of Oral Medicine, Faculty of Dentistry, Baiturrahmah University, Padang, Indonesia \\ ${ }^{2}$ Department of Pediatric Dentistry, Faculty of Dentistry, Baiturrahmah University, Padang, Indonesia \\ ${ }^{3}$ Program of Dental Profession, Faculty of Dentistry, Baiturrahmah University, Padang, Indonesia \\ ${ }^{4,5}$ Department of Food Science and Biotechnology, Dayeh University, Dacun, Changhua, Taiwan
}

\begin{abstract}
Candidiasis is a primary or secondary infections caused by fungi of the genus Candida, especially Candida albicans. Candidiasis is callled opportunistic infectious agents. This relates to local or systemic factors, which are caused due to antibiotics, corticosteroid, xerostomia, systemic disorders such as diabetes or immune defects, immunosuppressive treatment, AIDS, leukemia and lymphoma as well as chemotherapy. A 53-year-old male patient came to Baiturrahmah Dental Academic Hospital with complaints of pain on the tongue since 2 weeks ago and felt his mouth feel dry and uncomfortable and suspected to be diagnosed acute pseudomembran candidiasis. Management of the case was topical anti-fungal drugs such as nystatin oral suspension, vitamin $\mathrm{C}$, and a topical antiseptic mouthwash containing heksetidin. Education about hygiene and oral health, as well as a healthy diet was given to the patient. Investigations such as blood tests recommended in patients to investigate the possibility of systemic disease (high leucocyte and erythrocyte sedimentation rat/ESR) L associated with oral lesions in patients.
\end{abstract}

Keywords : Candidiasis, Management, ESR

\section{Introduction}

Various infectious diseases that affect the body that are associated with changes in oral mucosa. These infections can be bacterial, viral and parasitic infections. Candidiasis is one of the lesions in the oral cavity that often occurs associated with immunodeficiency. This lesion is a primary or secondary infectious disease caused by fungi of the genus Candida, especially Candida albicans. Candidiasis may occurs due to an impaired immune response. Also called an opportunistic infectious agent, which can cause disease if the body's defense mechanism is disrupted [1] [2] [3].

Candidiasis can be white and red lesions, candidiasis is divided into 5 types based on clinical features and other infectious history, including acute pseudomembrane (thrush), acute atrophic candidiasis (antibiotic evening mouth), chronic atrophic candidiasis (chronic denture stomatitis), chronic keratotic candidiasis (hyperplastic), and angular cheilitis [1]. Clinical features of acute pseudomembranous candidiasis (thrush) appear as clustered, diffuse, clotted white mucosal plaques that can be removed and leave the surface red, rough, or bleeding. This is a normal microflora disorder in the mouth that becomes a pathogen associated with local and systemic factors, including caused by antibiotics, costicosteroids, xerostomia, sufferers 
who become weak due to systemic diseases or immune defects such as diabetes, immunosuppression, AIDS, anemia, leukemia and lymphoma and chemotherapy. Usually found on the buccal mucosa, tongue, and soft palate. These lesions are usually accompanied by minimal symptoms, but in severe cases can cause burning, dysphagia (difficulty swallowing), uncomfortable feeling in the mouth such as metallic taste, bitter, salty [1] [4] [5][6][7][8] [9].

Acute atrophic candidiasis (antibiotic sore mouth) is an infection that occurs due to the use of broad spectrum antibiotics. This infection has an imbalance in the oral ecosystem between Lactobacillus acidophilus and Candida albicans, where there is a decline in the population of lactobacillus and allows candida to thrive due to the use of antibiotics. Acute atrophic candidiasis causes the mucosal surface to peel and appear as diffuse red spots that do not arise, if the tongue is generally found on the surface without the filiform papillae, pain such as burning and itching is the main complaint. Chronic atrophic candidiasis (denture stomatitis) in the form of red lesions is mostly found in patients with complete denture and some who use denture during sleep [1] [5] [6] [8][10].

Chronic keratotic candidiasis (hyperplastic) is generally found in the labial commissure in the form of white patches that cannot be removed so that the diagnosis must be determined by biopsy5. In addition, angular cheilitis caused by Candida albicans clinically appears red and cracked or in the form of fissures at the corners of the lips, often found in elderly and toothless patients. Angular cheilitis can also be caused by various factors, such as Candida albicans, nutritional deficiencies such as Fe, Vitamin B, Folic Acid, or a combination with candidiasis and bacterial infections [3]. This case report will describe patients with a clinical picture of acute pseudomembranous candidiasis accompanied by xerostomia, angular cheilitis, and suspected systemic infections (high leucocyte and ESR).

\section{Case Report}

A 53-year-old male patient came to Baiturrahmah Dental Academic Hospital with complaints of pain on the tongue since 2 weeks ago, and felt his mouth feel dry and uncomfortable. Patient s said there were white spots that are increasingly clear on the surface of the tongue, and increasingly sore every day. The tongue's surface gets more sore when the patient eats spicy food, and decreases when the patient drinks warm water. The patient was afebris and the pain of his tongue has never been treated. Extra oral examination is known to be not palpable submandibular glands. Intra-oral examination shwed white plaques, such as velvet which can be wiped and leave a rough surface on the dorsum of the tongue and buccal mucosa. In addition, the surface of the tongue is red with atrophy of the filiform and papillary papilla, angular cheilitis in the form of red fissures on the right and left corners of the lips (Figure 1). There were periodontal abscess in tooth 14 , radic in all regions of the teeth in the maxilla except missing regions $12,21,36,46$. The patient's oral hygiene is poor.The patient suspected to be diagnosed acute pseudomembranous candidiasis. 

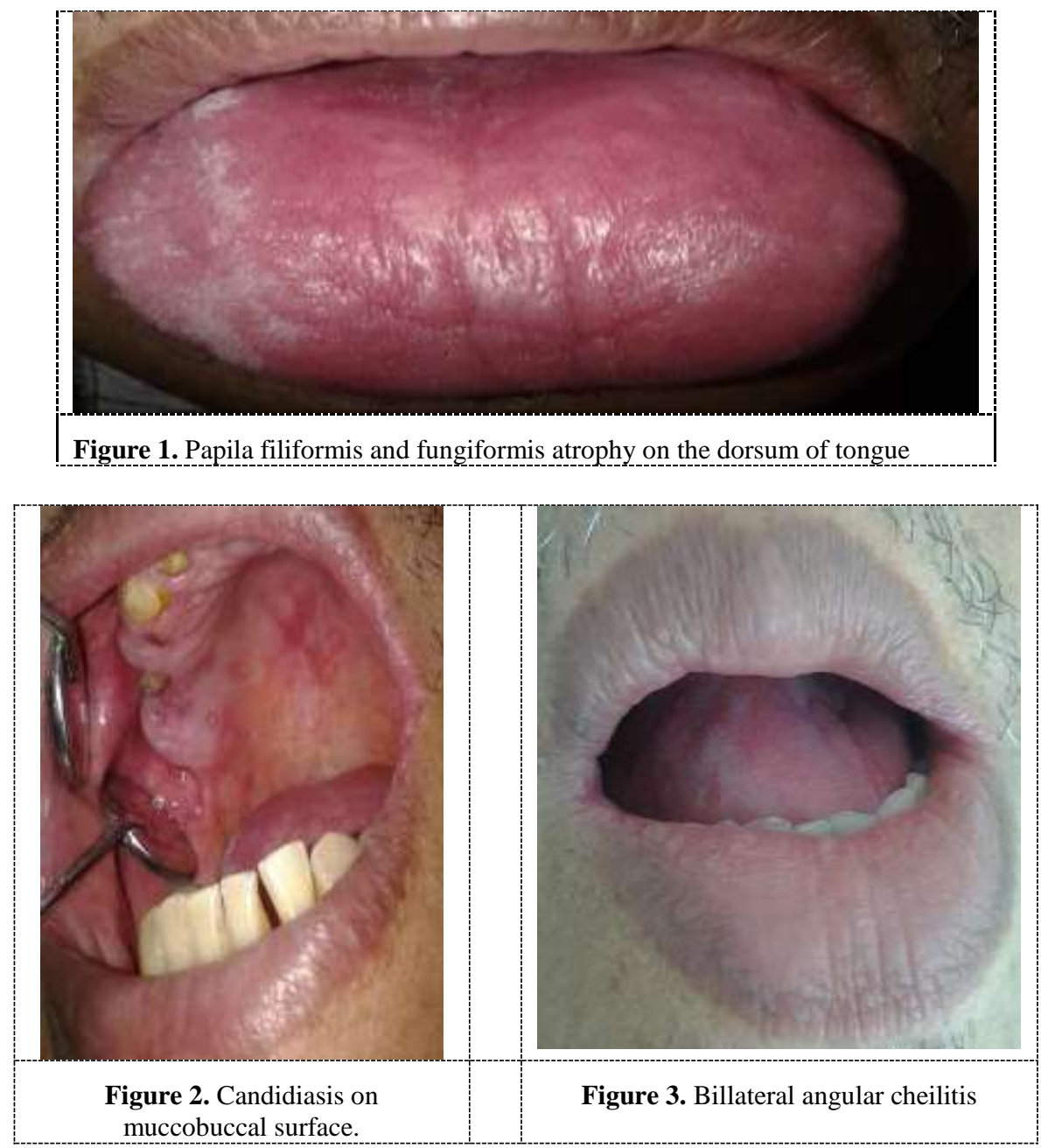

\section{Case management}

Management was the administration of a topical anti-fungal drug of an oral nystatin 4 times a day by means of the drug being dropped into the mouth and left temporarily before being swallowed. In addition, $500 \mathrm{mg}$ of vitamin $\mathrm{C}$ as many as 10 tablets taken 1 time a day after meals. Topical antiseptics mouthwash containing hexetidine were also given, consumed in the morning and evening as much as $15 \mathrm{ml}$ for 30 seconds.

Education about dental and oral health was provided. Investigation in the form of referral laboratory tests with blood tests was also investigated to find out the possibility of systemic diseases associated with oral lesions in patient.

The first control in the patient was done after the first visit. The pain on the surface of the tongue was reduced. The oral condition changes were not sigificant. White plaques were still found on the mucosa, the dorsum of the tongue and the lower part of the tongue were partial 
atrophy of the filiform and fungiform papillae, and slight red fissures at the corners of the lips (Fig. 2). On a complete blood test in UPTD Balai Laboratorium Kesehatan, West Sumatera (No. K.5910/LHU/BLK-SB/XI/2014), it is known that there was an increase in the number of leukocytes and the ESR that exceeds normal . Topical anti-fungal drugs in the form of oral nystatin suspension were re-prescribed to the patient.

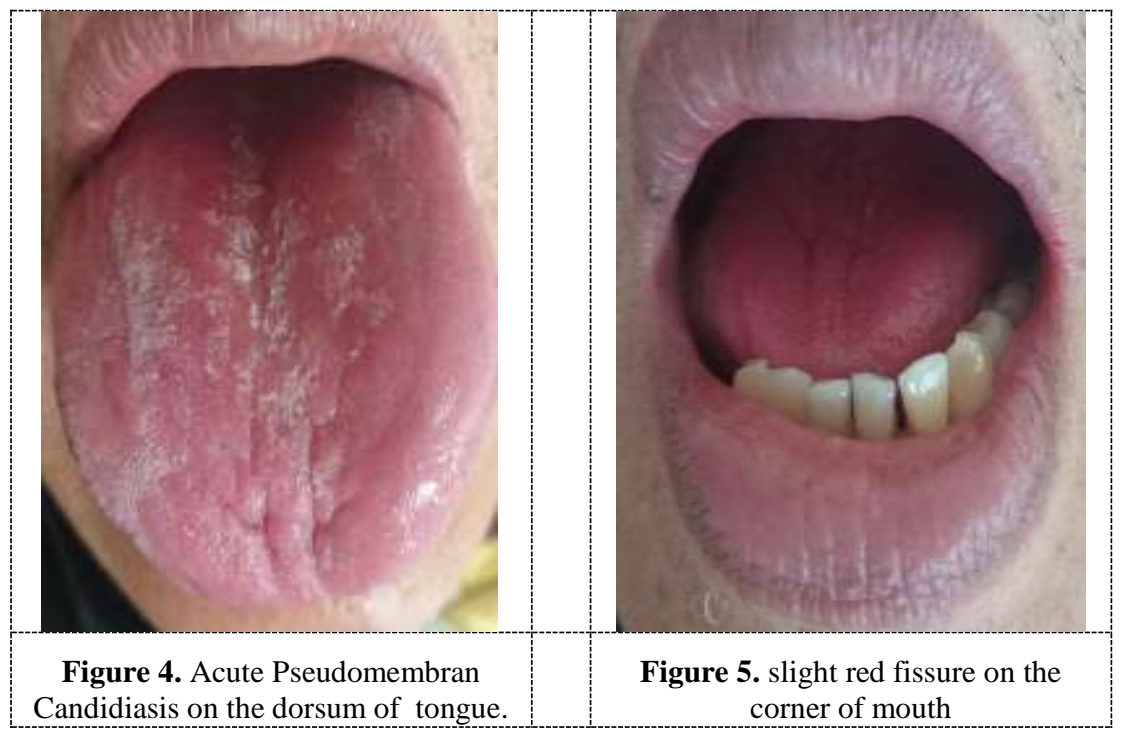

Table 1. Results of complete blood tests and peripheral blood images showing increased numbers of leukocytes and ESR, and neutrophilic leukocytosis shift to the left

\begin{tabular}{|c|c|c|c|c|c|}
\hline No & Parameter & Unit & Reference Score & Results & $\begin{array}{l}\text { Method } \\
\text { Specification }\end{array}$ \\
\hline 1 & Haemoglobin & $\mathrm{g} / \mathrm{dl}$ & $13.0-18.0$ & 13.1 & $\begin{array}{l}\text { Autohemotology } \\
\text { Analyzer }\end{array}$ \\
\hline 2 & Leukocyte & $/ \mathrm{mm}^{3}$ & $4,000-11,000$ & 16,500 & Impedance \\
\hline 3 & $\begin{array}{l}\text { Erythrocyte } \\
\text { sedimentation rate }\end{array}$ & $\mathrm{mm} / \mathrm{hour}$ & $<10$ & 106 & Westergren \\
\hline \multirow[t]{6}{*}{4} & Basophil & $\%$ & $0-1$ & 0 & Microscopic \\
\hline & Eosinophil & $\%$ & $1-3$ & 1 & Microscopic \\
\hline & Stem neutrophil & $\%$ & $2-6$ & 8 & Microscopic \\
\hline & Segment neutrophil & $\%$ & $50-70$ & 72 & Microscopic \\
\hline & Lymphocyte & $\%$ & $20-40$ & 16 & Microscopic \\
\hline & Monocyte & $\%$ & $2-8$ & 3 & Microscopic \\
\hline 5 & Erythrocyte & $/ \mathrm{mm}^{3}$ & 4.5-5.5 millions & 3.97 millions & Impedence \\
\hline 6 & Thrombocyte & $/ \mathrm{mm}^{3}$ & $150-400$ thousands & 345 thousands & Impedence \\
\hline 7 & Hematocrit & Vol\% & $40-50$ & 38 & $\begin{array}{l}\text { Autohemotology } \\
\text { Analyzer }\end{array}$ \\
\hline 8 & $\mathrm{MCV}$ & $\mu^{3}$ & $82-92$ & 95 & $\begin{array}{l}\text { Autohemotology } \\
\text { Analyzer }\end{array}$ \\
\hline 9 & $\mathrm{MCH}$ & Pikogram & $27-31$ & 33 & $\begin{array}{l}\text { Autohemotology } \\
\text { Analyzer }\end{array}$ \\
\hline 10 & $\mathrm{MCHC}$ & $\%$ & $32-36$ & 35 & $\begin{array}{l}\text { Autohemotology } \\
\text { Analyzer }\end{array}$ \\
\hline
\end{tabular}




\begin{tabular}{|c|c|c|c|c|c|}
\hline No & Parameter & Unit & Reference Score & Results & $\begin{array}{l}\text { Method } \\
\text { Specification }\end{array}$ \\
\hline \multirow[t]{4}{*}{11} & $\begin{array}{l}\text { Peripheral blood } \\
\text { cells }\end{array}$ & - & - & - & - \\
\hline & Erythrocyte & - & - & $\begin{array}{l}\text { Nomochrome } \\
\text { anisitosis }\end{array}$ & Microscopic \\
\hline & Leucocyte & - & - & $\begin{array}{l}\text { Leucocytosis } \\
\text { neutrophilia } \\
\text { shift to the left } \\
\text { with } \\
\text { neutrophil } \\
\text { degeneration } \\
\text { sign. }\end{array}$ & Microscopic \\
\hline & Thrombocyte & - & - & $\begin{array}{l}\text { Sufficient } \\
\text { number }\end{array}$ & Microscopic \\
\hline
\end{tabular}

\section{Discussion}

In addition to subjective and objective examination, patients were also advised to carry out blood tests to find out if there was manifestation of systemic diseases. From the results of a complete blood test, it was found that there was an increase in the number of leukocytes and ESR that exceeded normal in patients, namely the number of leukocytes was $16,500 / \mathrm{mm} 3$ and the ESR was $106 \mathrm{~mm} /$ hour. This proves that there is an inflammatory process in the patient's body. Increased leukocytes / leukocytosis was a normal response to infection or inflammatory processes. Increased ESRs accompany most inflammatory diseases, both local and systemic. Most acute and chronic inflammatory diseases and neoplasms are associated with increased ESR [9] [11] [12]. On complete blood tests, increased neutrophil counts indicate bacterial sepsis [13].

The results of examination of peripheral blood images in patients showed neutrophilic leukocytes shift to the left with signs of neutrophil degeneration. Shift to the left was the term used to explain the increase in the proportion of immature leukocytes (usually neutrophils) found in the blood of people who was infected[11] [12]. This showed an infection in the patient's body. Acute pseudomembranous candidiasis in the case is a normal microflora disruption in the mouth that is thought to be associated with xerostomia, leukocyte damage, and patients who become weak due to systemic disease [4].

Correcting local causes such as hyposalivation, improving oral hygiene, and using antifungal agents were the standard management4. Management in the above case is the administration of a topical anti-fungal drug in the form of an oral suspension containing 100,000 IU nystatin. The shape of the suspension was easier to use in patients suffering from xerostomia which may be difficult to dissolve the tablet [4] [8] [10] [14]. Nystatin was an antifungal antibiotic derived from Streptomyces noursei, which works fungistatic, damaged the fungal cell wall. Nystatin binded to ergosterol, where ergosterol was needed for the formation of fungal cell walls. This may resulted in damage to the cell membrane and increased permeability, so that the intracellular components that were important for cell life seep out and eventually the fungal cells will die [2] [10] [15].

In addition, oral administration of vitamin $\mathrm{C}$ was useful to help healing process, and play a role in the formation of collagen. Collagen was a protein compound that affects the structural integrity of all connective tissues so that it played a role in wound healing. In 
addition, it increases the absorption and metabolism of Fe, Vitamin $\mathrm{C}$ was generally found in vegetables and fruits[16] [17].

Topical antiseptics of mouthwash containing $0.1 \%$ hexetidine were also given to improve oral hygiene. Hexetidine was a broad-spectrum antibacterial with low concentration useful for microorganisms in the oral cavity. Hexetidine had antibacterial properties, useful for Gram positive and Gram negative bacteria, and reduced inflammation. In addition, this mouthwash was used for oral thrush and maintaining oral hygiene [18]. Healing of candidiasis was not seen at the time of contro. The white plaque grows larger and spreads on the dorsum of the tongue (Figure 3). Recurrent candidiasis can be a symptom or sign of a poor health problem4. In this case, the patient-given medical referrals for internal medicine specialists. In addition to giving topical anti-fungal and topical antiseptic drugs, patient was instructed to maintain the cleanliness of the oral cavity and undergo a healthy diet.

\section{Conclusions}

Acute pseudomembranous candidiasis is one type of candidiasis which is a primary or secondary infectious disease caused by fungi of the genus Candida, especially Candida albicans. Candidiasis is often referred to as an opportunistic infectious agent. Candidiasis in patients is thought to be associated with xerostomia, leukocyte damage, and patients who become weak due to systemic diseases, because from the results of blood tests showed an increase in the number of leukocytes and ESR. Management was the administration of topical anti-fungal drugs in the form of oral nystatin suspension, vitamin C $500 \mathrm{mg}$, and topical antiseptics in the form of mouthwash containing hexetidine. In addition, education regarding hygiene and dental and oral health, and a healthy diet are also given to patients.

\section{Acknowledgments}

Thank you for all the elements involved in this research.

\section{References}

[1] Ibsen O A C and Phelan J A 1992 Oral Pathology for the Dental Hygienist (Philadelphia P A:: W.B. Saunders Company)

[2] Scully C 2014 Scully's Medical Problems in Dentistry E-Book (China:Elsevier Health Sciences)

[3] Singh A, Verma R, Murari A and Agrawal 2014 J Oral Maxillofac Pathol 18 S81-S5 [4] Scully C 2008 Oral and Maxillofacial Medicine: The Basis of Diagnosis and Treatment (UK: Elsevier)

[5] Langlais R P and Miller C S 2003 Color Atlas of Common Oral Diseases (Philadelphia:Lippincott Williams \& Wilkins)

[6] Neville B W 2002 Oral \& Maxillofacial Pathology (Philadelphia:W.B. Saunders) 
[7] Pindborg J J 1973 Atlas of Diseases of the Oral Mucosa (Philadelphia:Saunders)

[8] Coulthard P 2008 Master Dentistry Text and Evolve EBooks Package: Volume 1: Oral and Maxillofacial Surgery, Radiology, Pathology and Oral Medicine (Edinburgh:Elsevier Health Sciences)

[9] Bensadoun R J, Patton L L, Lalla R V and Epstein J B 2011 Support Care Cancer 19737

[10] Lyu X, Zhao C, Yan Z-M and Hua H 2016 Drug design, development and therapy 101161

[11] Corwin E J 2008 Handbook of Pathophysiology (Philadelphia:Wolters Kluwer Health/Lippincott Williams \& Wilkins)

[12] Sacher R A, McPherson R A, Campos J M and Widmann F K Widmann's Clinical Interpretation of Laboratory Tests (Philadelphia:Davis)

[13] Davey P 2010 Medicine at a Glance (Chicester: Wiley) [14] Garcia-Cuesta C, Sarrion-Pérez M-G and Bagán J V 2014 Journal of Clinical and Experimental dentistr 6 e 576

[15] Woo T M and Wynne A L 2011 Pharmacotherapeutics for Nurse Practitioner Prescribers (Philadelphia:F.A. Davis Company)

[16] Almatsier S 2010 Prinsip dasar ilmu gizi (Jakarta:Gramedia Pustaka Utama)

[17] Sroda R 2009 Nutrition for a Healthy Mouth (Philadelphia:Lippincott Williams \& Wilkins)

[18] Jeske A H 2013 Mosby's Dental Drug Reference (Texas:Elsevier - Health Sciences Division) 